\title{
Alinhamento interpessoal, REPRESENTACIONAL E morfossintático na Gramática Discursivo-FunCional
}

(Interpersonal, representation and morphosyntactic alignment in Functional Discourse Grammar)

\author{
Kees Hengeveld \\ (Universidade de Amsterdã) \\ J. Lachlan MACKENZIE \\ (VU University Amsterdam e ILTEC, Lisboa)
}

\begin{abstract}
Within the framework of Functional Discourse Grammar (FDG), alignment concerns the relations between the Interpersonal, Representational and Morphosyntactic Levels of grammar. This article proposes a typology of languages based upon what we find to be encoded in their morphosyntactic organization: pragmatic distinctions (as in Tagalog), semantic distinctions (as in Acheb), or distinctions inherent to the morphosyntax (as in English, Basque and Kham). By including both subject and object, and both accusative and ergative languages in our treatment of morphosyntactic alignment, we provide a better coverage of typological variation and show the potential of FDG for cross-linguistic analysis.

KEY-WORDS: Interpersonal alignment; Functional Discourse Grammar; morphosyntactic alignment.
\end{abstract}

REsumo: Este artigo se debruça sobre o mapeamento entre os Niveis Interpessoal, Representacional e Morfossintático da gramática, o chamado alinhamento, segundo o arcabouço da Gramática Discursivo-Funcional (GDF). Propõe uma tipologia das linguas baseada no que a sua organização morfossintática codifica: distinções pragmáticas (p.ex. em Tagalo), distinções semânticas (p.ex. em Achém), ou distinções inerentes à morfossintaxe (p.ex. em Inglês, Basco ou a língua Kham). A inclusão tanto do Sujeito como do Objeto e de linguas tanto acusativas como ergativas no tratamento do alinhamento morfossintático permitiu-nos abranger tipos tipologicamente mais variáveis e demonstrar o potencial da GDF para a análise contrastiva das línguas.

PaLAVRAs-CHAVE: Alinhamento interpessoal; Gramática Discursivo-Funcional; alinhamento morfossintático. 


\section{Introdução}

Neste artigo, analisamos o alinhamento interpessoal, representacional e morfossintático sob a perspectiva da Gramática Discursivo-Funcional. O artigo compreende três partes: na primeira, faremos uma breve introdução à Gramática Discursivo-Funcional: depois, consideraremos os três tipos de alinhamento mencionados no título e, por fim, formularemos algumas conclusões. ${ }^{1}$

A Gramática Discursivo-Funcional (GDF; Hengeveld e Mackenzie 2008) é a versão mais nova da Gramática Funcional do falecido lingüista Simon C. Dik. Neste modelo tentamos descrever as unidades lingüísticas a partir da aplicação de quatro níveis de análise que se situam no componente gramatical. Dois desses níveis modulares dão conta das motivações pragmáticas (o Nivel Interpessoal) e das motivações semânticas (o Nivel Representacional) da formulação lingüística. Os outros níveis representam os aspectos estruturais (o Nível Morfossintático) e prosódicos (o Nível Fonológico) da codificação dos enunciados. Veja Figura 1.

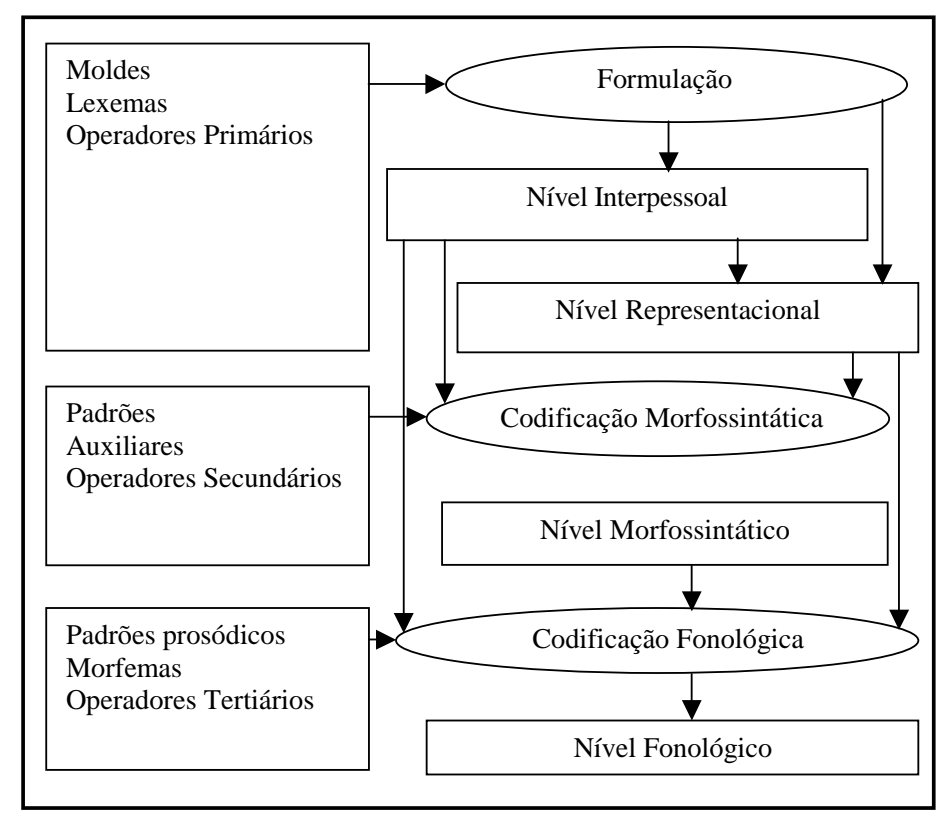

Figura 1: Sinopse da Gramática Discursivo-Funcional

\footnotetext{
1 Este artigo, de responsabilidade dos dois autores, se beneficia das discussões e trocas acadêmicas com colegas e ainda dos comentários dos pareceristas. Não podemos deixar de mencionar em
} 
O nome "Gramática Discursivo-Funcional" deriva-se do fato de nos concentrarmos sobre o ato discursivo, o que quer dizer que não nos restringimos a orações completas; abrangemos igualmente tanto as unidades maiores quanto as menores do que as orações completas. Na descrição de atos discursivos, reconhecemos a necessidade de postular tanto um componente gramatical quanto três componentes adicionais que interagem com o componente gramatical: o componente conceitual, onde surge a intenção comunicativa; o componente contextual, onde se armazenam todos os aspectos da comunicação que podem influenciar o funcionamento do componente gramatical; e o componente de saída, responsável pela tradução da representação fonológica do ato discursivo para a forma fonética. Neste artigo vamos enfocar o componente central, a gramática propriamente dita.

Postulamos que o componente gramatical é tanto mais efetivo quanto mais sua organização se assemelhar à produção lingüística do indivíduo. Assim, como a produção começa com as intenções comunicativas e procede em direção descendente até a articulação, propomos uma implementação dinâmica da gramática que começa com a informação que provém do componente conceitual e termina com uma representação fonológica a ser transmitida ao componente de saída.

A implementação dinâmica da gramática se inicia com a formulação. Essa operação implica duas análises do ato discursivo que se processam nos chamados Níveis Interpessoal e Representacional; estes, por sua vez, contêm uma representação de todos os aspectos gramaticais do ato discursivo que dizem respeito à pragmática e à semântica respectivamente. Ambos os níveis operam com três tipos de primitivos: moldes, lexemas e operadores primários. No Nível Interpessoal, os moldes inventariam os recursos gramaticais que estão disponíveis em cada língua para se fazerem as distinções que dizem respeito à interação verbal, tais como ilocuções de base, funções pragmáticas (Tópico, Foco, etc.), diferenciações sociais (p. ex. pronomes e formas de tratamento deferenciais e informais, etc. Os lexemas introduzidos neste nível incluem nomes próprios, locuções que modificam o ato ilocutivo (p.ex. em poucas palavras), marcadores discursivos, etc. Os operado-

especial os inestimáveis conselhos de Maria Luisa Braga (UFRJ). O artigo se baseia em resultados que também foram publicados em língua inglesa em Hengeveld e Mackenzie (2008: 316-332). A contribuição de Mackenzie foi parcialmente financiada pelo Ministério das Ciencias e da Inovação de Espanha, projeto no. HUM2007-62220. 
res primários do Nível Interpessoal são elementos passíveis de instigar processos nos Níveis Morfossintático e Fonológico, p.ex. operadores de reportatividade, de identificabilidade ou de genericidade. O núcleo do ato discursivo é o conteúdo comunicado (C), que contém um conjunto de subatos: subatos de atribuição $(\mathrm{T})$ e subatos de referência $(\mathrm{R})$. Uma fórmula como $(+\mathrm{i}$ + s $\left.\mathrm{R}_{\mathrm{P}}\right)_{\mathrm{TOP}}$ - veja Figura 2 mais em baixo - quer dizer: "Um sub-ato de referência que tem a função pragmática de Tópico e operadores de identificabilidade $( \pm$ i) e de especificidade ( \pm s) com valor positivo".

No Nível Representacional, os moldes indicam que recursos gramaticais estão disponíveis em cada língua para o estabelecimento de distinções semânticas; por exemplo, as várias categorias de designação (p.ex. animado/ inanimado), as funções semânticas (Ator, Paciente, Recipiente, Lugar, ...), as oposições de número (singular, dual, plural, ...), etc. É aqui que se introduz a maioria dos lexemas, inclusive os advérbios que modificam o conteúdo proposicional (obviamente, a título de exemplo). Os operadores primários desse nível abrangem a evidencialidade, o tempo absoluto e relativo, a polaridade, etc. O núcleo do ato discursivo é a predicação $\left(\mathrm{e}_{1}\right)$, constituída por um conjunto formado por uma propriedade $\left(\mathrm{f}_{1}\right)$ e vários argumentos $\left(\mathrm{x}_{1},-\right.$ ); distinguiremos neste artigo predicações mono-, bi- e triargumentais. Além de argumentos, reconhecemos modificadores, com funções semânticas como por exemplo Instrumento. Uma fórmula como $\left(\mathrm{x}_{\mathrm{j}}:-\mathrm{isda}-\left(\mathrm{x}_{\mathrm{j}}\right)\right)_{\mathrm{U}}-$ veja Figura 2 abaixo - quer dizer: "Um argumento que designa uma entidade $\left(\mathrm{x}_{\mathrm{j}}\right)$ de primeira ordem que tem como núcleo um lexema isda com a função semântica de Paciente". ${ }^{2}$

$\mathrm{Na}$ implementação dinâmica, procedemos na direção dos dois processos de codificação que geram os Níveis Morfossintático e Fonológico; estes contêm, por sua vez, uma representação de todos os aspectos formais do ato discursivo. Os processos de codificação também operam com primitivos, isso é, padrões, auxiliares, morfemas e operadores secundários e tertiários. Neste artigo, não levaremos em consideração o Nível Fonológico, mas, quanto ao Nível Morfossintático, diversos aspectos dele vão reaparecer nas seções seguintes. Nas línguas em que as noções de Sujeito e Objeto são gramaticalmente relevantes, essas funções sintáticas são atribuídas no Nível

2 Traduzimos o termo inglês 'Undergoer' (Hengeveld \& Mackenzie 2008: 195) por Paciente. Damo-nos conta que essa tradução é restrita em face do sentido que Foley (2005) atribui ao "Undergoer". 
Morfossintático. E é aqui que surgem as camadas morfossintáticas tais como oração, frase, palavra, clítico, morfema, etc. e é aqui que se impõem as relações de concordância.

\section{Alinhamento}

\subsection{Três tipos de alinhamento}

Na GDF, o termo alinhamento é usado para designar o mapeamento de unidades pragmáticas e semânticas em unidades morfossintáticas. Foley (2005: 385) define (o mapeamento como o modo de alinhar argumentos lexicalmente especificados de um predicado com suas manifestações estruturais, formais. ${ }^{3}$ Em muitas teorias, a descrição do alinhamento recorre a relações gramaticais como Sujeito e Objeto, consideradas universais. Em nossa teoria, Sujeito, Objeto, etc. são também denominadas funções sintáticas e, como tal, localizam-se ao Nível Morfossintático; no entanto, na GDF, só se atribuem as funções sintáticas quando as propriedades formais das unidades lingüísticas não se reduzem às categorias pragmáticas e semânticas subjacentes. Nas palavras de Siewierska \& Bakker (no prelo; manuscrito: 1), as funções sintáticas são identificáveis em termos da presença de neutralizações restritas das distinções semânticas e pragmáticas. ${ }^{4}$ Quando não ocorre neutralização, assumimos que as funções sintáticas não estão presentes na gramática do ato discursivo, como diz também Falk (2006). Por conseguinte, reconhecemos três tipos de alinhamento:

1. Alinhamento interpessoal: a organização morfossintática reflete a organização do Nível Interpessoal no que diz respeito quer às funções pragmáticas (Tópico, Foco, etc.) quer às propriedades referenciais (identificabilidade, especificidade, etc.).

2. Alinhamento representacional: a organização morfossintática reflete a organização do Nível Representacional no que diz respeito quer às funções semânticas (Ator, Paciente, etc.) quer à designação (oposição animado/inanimado, pessoa gramatical, etc.).

3 Cf. o original: "how to align lexically specified arguments of a predicate with their formal, structural realizations".

4 Cf. o original: "identifiable in terms of the presence of restricted neutralization of semantic and pragmatic distinctions". 
3. Alinhamento morfossintático: a organização morfossintática não é um espelho fiel nem da organização do Nível Interpessoal nem do Nível Representacional, exibindo, portanto, a sua própria organização. Esse nível diz respeito quer às já mencionadas funções sintáticas (Sujeito, Objeto) quer à complexidade dos constituintes (palavra, frase, oração, etc.).

A partir de tais pressupostos, podemos classificar as línguas de acordo com a organização da gramática de que dispõem; dito de outro modo: se uma gramática se organiza segundo princípios interpessoais, segundo princípios representacionais, ou, alternativamente ainda, segundo princípios morfossintáticos. O que é certo é que se trata de tendências, uma vez que, muitas vezes, as línguas podem exibir mistura de alinhamentos. Existem, por exemplo, línguas cujo alinhamento está sujeito tanto a fatores de referencialidade (fatores interpessoais) quanto a fatores de designação (fatores representacionais). Também se encontram línguas em que a concordância verbal está sujeita a fatores representacionais, enquanto a elipse nas orações subordinadas está sujeita a fatores morfossintáticos. Um artigo crucial para o entendimento desse assunto é o de Keenan (1976), em que se diferenciam as propriedades de codificação e de "comportamento gramatical" dos Sujeitos. Não obstante a complexidade acarretada pela "mistura" de sistemas, ao considerarmos os efeitos dos três tipos de alinhamento, vamo-nos restringir, nos parágrafos a seguir, a alguns exemplos relativamente puros.

\subsection{Alinhamento interpessoal}

Um exemplo bastante interessante de alinhamento interpessoal encontra-se em Tagalo, uma língua filipina. Para investigar o sistema de alinhamento dessa língua, já submetido a várias análises divergentes, seguimos a proposta de Bickel (no prelo; manuscrito: 8), segundo a qual, na análise dos sintagmas nominais que começam com o proclítico ang, "o que importa mais é que o SN tenha referência específica e seja o elemento mais tópico no discurso" Como se vê, trata-se claramente de fatores interpessoais. Ilustremos esse caso com os exemplos em (1-3):

5 Cf. o original: "all that matters is that the NP has specific reference and that it is the most topical element in discourse". 
Tagalo
(1) bumilí ang=lalake ng=isda sa=tindahan PFV.A.comprar SPEC.TOP=homem OBL=peixe $\mathrm{L}=$ loja 'O homem comprou peixe na/numa loja.'
(2) binilí ng=lalake ang=isda sa=tindahan. PFV.U.comprar OBL=homem $\quad$ SPEC.TOP=peixe $\quad$ L=loja 'O/um homem comprou o peixe na/numa loja.'
(3) binilhan ng=lalake ng=isda ang=tindahan PFV.L.comprar OBL=homem OBL=peixe $\quad$ SPEC.TOP=loja 'O/um homem comprou peixe na loja.'

Além de estar sujeito a fatores interpessoais, o marcador ang interage com o Nível Representacional na expressão do predicado das orações. A forma do predicado depende da função semântica da unidade representacional que corresponde ao subato com função tópica, no Nível Interpessoal. Em (1), vê-se que o Tópico é Ator (A), em (2) que ele é Paciente (U para Undergoer), e em (3) que se trata de um Lugar (L). O marcador ang esconde a função semântica do sintagma nominal, mas a forma do predicado permite ao/à ouvinte desvendar a função semântica implícita. Na Figura 2 vêem-se as correspondências entre os Níveis Interpessoal, Representacional e Morfossintático para os três exemplos analisados:

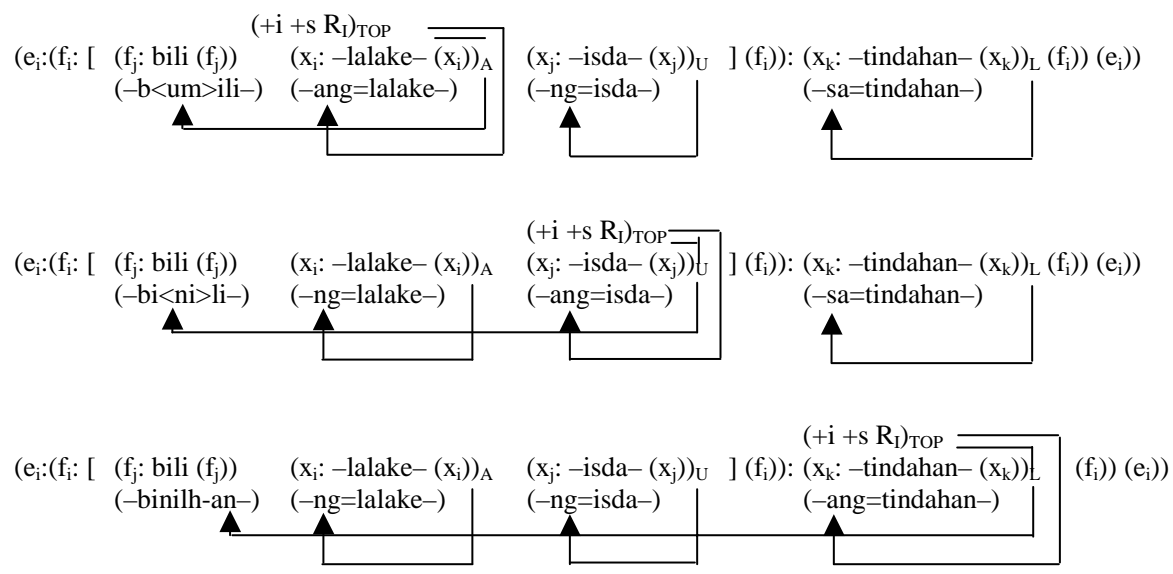

Figura 2: Correspondências entre os Níveis Interpessoal, Representacional e morfossintático nos exemplos (1-3) 
O que queríamos salientar é que não é preciso postular funções sintáticas na língua Tagalo. Para a codificação morfossintática, basta, por um lado, identificar a unidade que expressa o Tópico e depois marcá-la com ang e, por outro, saber qual é a função semântica dessa unidade para escolher a forma apropriada do predicado. Na terminologia de Keenan (1976), trata-se aqui de propriedades de codificação. Quanto ao comportamento gramatical, observa-se a mesma situação: a elipse nas orações coordenadas em Tagalo só se aplica às frases com ang, o que quer dizer que esse processo depende de fatores puramente interpessoais. Podemos então predizer que a marcação com ang será insensível à distinção entre argumentos e modificadores, pois essa distinção não se aplica ao Nível Interpessoal. Na verdade, na língua Tagalo, vários tipos de unidades semânticas podem corresponder ao Tópico, inclusive modificadores do estado-de-coisas, tais como o locativo em (3), apresentado anteriormente. Observe também, no exemplo contido em (4), que o sintagma com ang (que neste exemplo manifesta uma forma demonstrativa itóng) exerce função semântica de modificador, mais especificamente, de Instrumento (Himmelmann 2005):

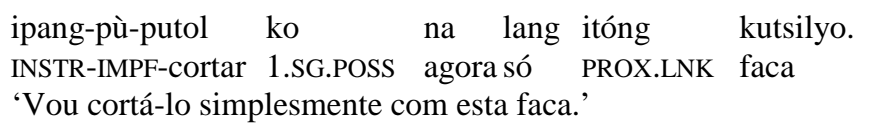

O fato de ser a marcação insensível à distinção entre argumentos e modificadores é compatível com o fato de que tanto argumentos como não-argumentos com a mesma função semântica conduzem ao mesmo tipo de marcação do predicado. Por exemplo, tanto argumentos locativos como modificadores locativos, desde que tópicos, induzem ao uso da forma locativa do predicado.

\subsection{Alinhamento representacional}

Os sistemas de alinhamento representacional podem ser sensíveis quer à função semântica quer à designação de uma unidade, possibilidades a serem consideradas a seguir.

\subsubsection{Funções semânticas}

Uma língua da Indonésia na qual o alinhamento é sensível às funções semânticas é o Achém (ou Achinês ou Atjé). Na descrição mais completa 
dessa língua, a de Durie (1985), verifica-se tratar-se de uma língua sem Sujeito. Podem-se atribuir três funções semânticas aos argumentos dos predicados: Ator (A), Paciente (U) ou Recipiente (R). Atores e Pacientes animados ocorrem como sintagmas nominais ou como pronomes clíticos ao verbo, forma em que podem ainda ocorrer simultaneamente. Os pronomes que correspondem ao Ator são proclíticos e os que correspondem ao Paciente são enclíticos. Veja os exemplos contidos em (5-7): em (5), o Ator provoca o uso do proclítico lôn; em (6) o Paciente, induz ao uso do enclítico geuh: e em (7) vemos um verbo com dois clíticos.

(5) Lôn teungöh=lôn=jak.

1 centro $=1 . \mathrm{A}=\mathrm{ir}$

'Eu estou indo/andando.'

(6) Gopnyan galak=geuh that

3.POL feliz=3.POL.U muito

'Ele é muito feliz.'

(7) Gopnyan na=lôn=timbak=geuh

3.POL $\quad \mathrm{AUX}=1 . \mathrm{A}=$ disparar=3.POL.U

'Eu disparei nele.'

Pode-se marcar o Ator com a preposição lê, como se vê em (8), e o Recipiente com a preposição keu. Como já mencionado, não existem formas clíticas que correspondam aos Recipientes, como se vê em (8) (Durie 1985: 182):

(8)
Keu=jih $\quad$ ka=geu=jôk
buku=nyan lê=gopnyan.
$\mathrm{R}=3$.FAM $\quad \mathrm{INCH}=3 . \mathrm{POL} \cdot \mathrm{A}=\mathrm{dar} \quad$ livro=aquele $\mathrm{A}=3 . \mathrm{POL}$
'Ele (forma cortesa) deu-lhe (forma informal) aquele livro.'

Observe que, como o Paciente em (8) é inanimado, o verbo não dispõe de clítico Paciente.

Se ocorrer a topicalização de um argumento, a preposição desaparecerá. A posição do Tópico em Achém é a que precede diretamente o verbo. Como já vimos em (5) a supressão da preposição agentiva lê: lôn é provocada por razões de topicalização. A supressão da preposição dativa é exemplificada em (9) (Durie 1985: 182):

$\begin{array}{lll}\text { G) Gopnyan } \quad \mathrm{ka}=\mathrm{lôn}=\mathrm{bi} & \text { peng. } & \text { [gopnyan é Tópico] } \\ \text { 3.POL } & \mathrm{INCH}=1=\text { dar } & \text { dinheiro }\end{array}$


E o exemplo contido em (8) então? Ele não contradiz a nossa análise? Não, porque a topicalização não é obrigatória em Achém. Compare os exemplos (10) e (11):

(10) Keu=gopnyan lôn hana=galak=lôn. [a primeira unidade não é Tópico] DAT=3.POL 1.SG NEG.AUX $=$ gostar_de $=1$ 'Eu não gosto dele.'

(11) Gopnyan (*lôn) hana=galak=lôn. [a primeira unidade é Tópico] 3.POL 1.SG NEG.AUX=gostar_de $=1$

'Eu não gosto dele.'

Em (11), gopnyan, que exerce a função de Tópico, não permite que o argumento seguinte fique sem preposição; dito em outras palavras, lôn é Tópico em (10) e, como já dissemos, gopnyan é Tópico em (11).

É possível descrever todos esses fatos sem recorrer a funções sintáticas. Com efeito, em Achém, a forma dos argumentos reflete, primariamente, as funções semânticas; a função pragmática de Tópico oculta, secundariamente, a expressão dessas funções semânticas. Por conseguinte, a interação entre os três níveis pode ser ilustrada na Figura 3:

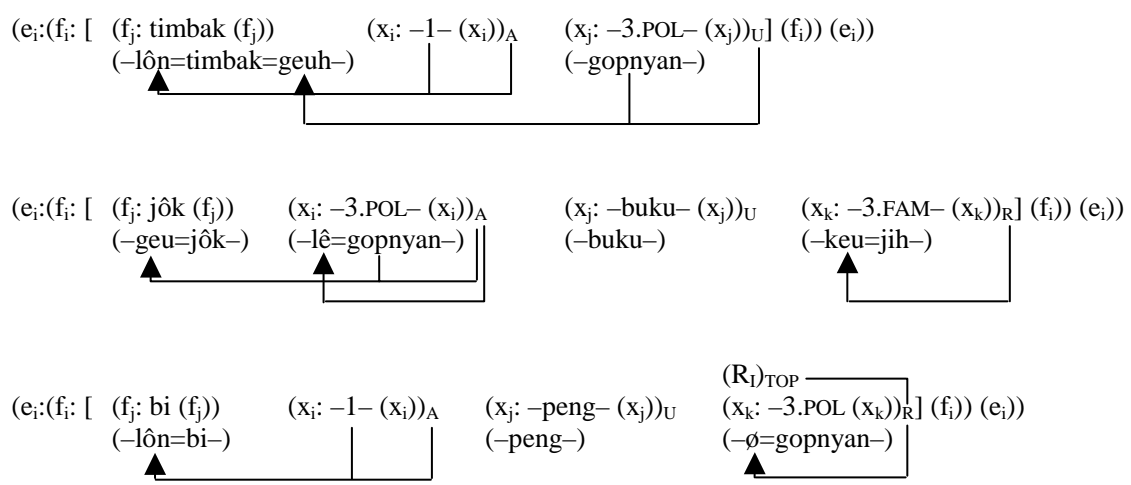

Figura 3: Correspondências entre os Níveis Interpessoal, Representacional e Morfossintático nos exemplos (7-9) 


\subsubsection{Designação}

O segundo tipo de alinhamento representacional chama-se alinhamento hierárquico, porque sua organização depende das hierarquias de animacidade e de pessoalidade. Um bom exemplo de uma língua que exibe este tipo de alinhamento é Plains Cree (uma língua que se fala no Canadá), conforme a descrição dada por Wolvengrey (2005). Os exemplos (12-13) ilustram alguns traços que desempenham um papel decisivo neste tipo de alinhamento:

(12) Ni-wîcih-â-nân-ak

1-ajudar-DIR-1.PL.3.PL

'Nós ajudamos eles.'

(13) Ni-wîcih-iko-nân-ak

1-ajudar-INV-1.PL.3.PL

'Eles nos ajudam.'

[o circunflexo $n i \ldots n a ̂ n=1 . \mathrm{PL} ;$ o sufixo $-a k=3 . \mathrm{PL}$ ]

Nesses dois exemplos, os mesmos marcadores de pessoa são usados para a expressão do plural da primeira pessoa (o circunfixo ni ... nân) e para o plural da terceira pessoa, independentemente das funções semânticas dos participantes, que são respectivamente Ator e Paciente. A codificação de tais orações obedece à hierarquia contida em (14), de acordo com a qual a segunda pessoa domina a primeira pessoa, e ambas dominam a terceira:

(14) 2

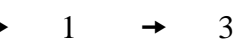

Se a pessoa que tem a posição superior na hierarquia for o Ator, o verbo exibirá a chamada marcação direta (DIR). Se a pessoa que tem a posição inferior na hierarquia for o Ator, o verbo exibirá a chamada marcação invertida (INV). Em (12), visto que a primeira pessoa domina a terceira e é também o Ator, usa-se a construção direta. Como em (13), a terceira pessoa é o Ator, aparece a forma invertida.

Quando houver dois argumentos da terceira pessoa, um deles receberá a chamada marcação proximativa e o outro a marcação obviativa. A terceira pessoa proximativa sempre domina a terceira pessoa obviativa, o que permite a elaboração da hierarquia (15a), como aponta Wolvengrey (2005: 424). Escolhe-se a marcação proximativa quando o argumento exercer a função pragmática de Tópico; (15a) equivale portanto a (15b): 


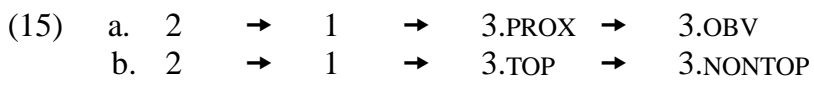

Os dois sistemas, o direto-inverso e o proximativo-obviativo, interagem, como se vê em (16-19), permitindo todas as combinações possíveis das funções pragmáticas e semânticas:

(16) Câniy- $\varnothing \quad$ kî-wîcih-ê-w Mêrî-wa.

João-PROX TNS-ajudar-DIR-3 Maria-OBV

'O João, ele ajudou a Maria.'

(17) Câniy-wa kî-wîcih-ê-w Mêrî- $\varnothing$.

João-OBV TNS-ajudar-DIR-3 Maria-PROX

'A Maria, ela ajudou o João.'

(18) Câniy-Ø kî-wîcih-ikw(-w) Mêrî-wa.

João-PROX TNS-ajudar-INV-3 Maria-OBV

'O João, a Maria ajudou.'

(19) Câniy-wa kî-wîcih-ikw(-w) Mêrî- $\varnothing$.

João-OBV TNS-ajudar-INV-3 Maria-PROX

'A Maria, o João ajudou.'

Em (16), João é Tópico e Ator, em (17), é não-Tópico e Paciente, em (18), Tópico e Paciente, e, finalmente, em (19), é não-Tópico e Ator. De forma analógica, Maria é não-Tópico e Paciente em (16), é, em (17), Tópico e Ator, em (18), é não-Tópico e Ator, e, finalmente, em (19) é Tópico e Paciente. A Figura 4 ilustra o sistema com a análise dos três níveis que subjazem a (16) e a (18):

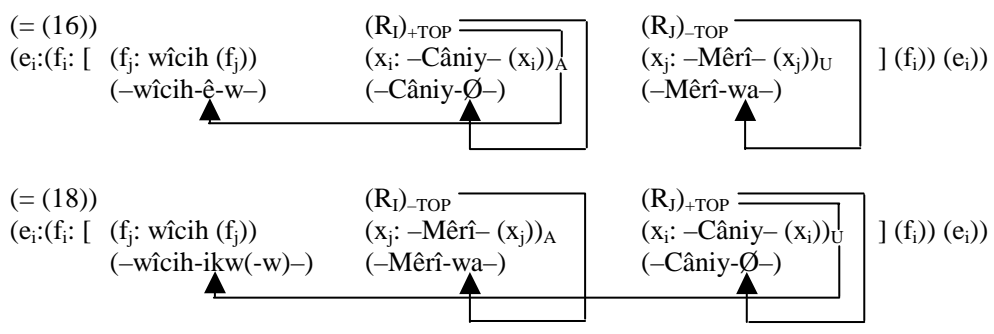

Figura 4: Correspondências entre os Níveis Interpessoal, Representacional e Morfossintático nos exemplos (16 ) e (18) 
O alinhamento hierárquico também é pertinente nas línguas em que a função sintática de Sujeito está presente na gramática mas não a de Objeto. Nesse tipo de língua, o argumento com a função semântica de Paciente pode alinhar-se de várias maneiras, conforme algumas exigências de natureza interpessoal e a posição dos traços do argumento numa hierarquia de designação. Por exemplo, em Espanhol, a marcação de um Paciente depende dos traços "humano" e "específico". Considere os exemplos contidos em (20-22):

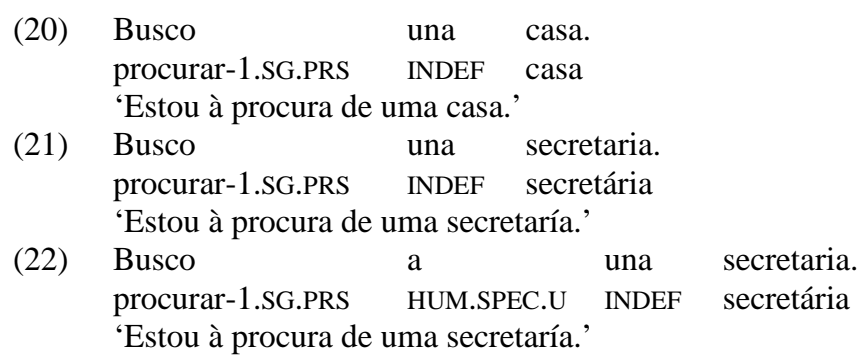

Emprega-se a oração (21) no caso de uma referência não-específica (um fator interpessoal), que seria apropriada num gênero textual como o anúncio. Usa-se (22) no caso de referência específica com o significado de que o/a falante anda à procura de uma pessoa que ele/ela já conhece. Podese utilizar o marcador $a$ tanto em referência definida quanto indefinida, contanto que seja específica. A hierarquia de designação abrange vários graus de animicidade: o marcador $a$ só se aplica a pessoas e a animais de estimação mas não a outros animais nem a entidades inanimadas.

\subsection{Alinbamento morfossintático}

O alinhamento morfossintático é sensível tanto às funções sintáticas atribuídas aos constituintes morfossintáticos quanto à complexidade desses constituintes. Comecemos com a influência das funções sintáticas.

\subsubsection{Funcõos sintáticas}

Nos casos em que a organização das unidades morfossintáticas não se reduz às funções e categorias pragmáticas e semânticas subjacentes, as fun- 
ções sintáticas se tornam relevantes. Consideremos os exemplos do inglês contidos em (23-24):
(23) The man walked. DEF homem andar.PST

O constituinte the man é Ator em (23) e Paciente em (24). Apesar disso, exibe o mesmo tipo de expressão em ambos os exemplos. No entanto, noutras circunstâncias é pertinente essa diferença entre as funções semânticas, como mostram os exemplos contidos em (25-27):

(25) The man saw a dog DEF homem vir.PST INDEF cão 'O homem viu um cão.'

(26) The dog was seen by the man. DEF cão AUX.PST vir.PRT A DEF homem 'O cão foi visto pelo homem.'

(27) the seeing of the dog by the man DEF vir.GER U DEF cão A DEF homem "lit. o ver do cão pelo homem" 'o fato de o homem ter visto o cão'

O Ator em (26) e (27) é introduzido pela preposição by, o Paciente em (27) pela preposição of, oposição que é neutralizada em (23) e (24).

A semelhança formal entre as duas ocorrências de the man em (23) e (24) também não se deriva da função pragmática do constituinte, que pode ser, em ambos os casos, ou topical ou focal, ou nenhuma. Por exemplo, (23) pode funcionar como resposta a qualquer das perguntas (28) até (30):
(28) What did the man do?
'O que fez o homem?'
(29) Who walked?
'Quem andou?'
(30) What happened?
'O que aconteceu?' 
Em tais casos, quando se produz neutralização das oposições pragmáticas e semânticas que, de outro modo, já desempenham um papel na organização da língua, deve-se atribuir o comportamento neutralizado dos constituintes morfossintáticos à presença de uma função sintática, que segundo a índole da neutralização - pode ser ou Sujeito ou Objeto.

Começemos com o Sujeito. Como já vimos nos exemplos ingleses, a função sintática Sujeito pode ser pertinente à análise de estruturas de predicados de um lugar predicacionais com um só argumento, se a língua neutralizar a distinção entre Ator e Paciente. Em línguas como o Inglês, pode-se alegar que a função de Sujeito é relevante na expressão de estruturas destituídas de qualquer argumento, já que nesse tipo de língua um Sujeito vazio se insere nestas construções, conforme se vê em (31):

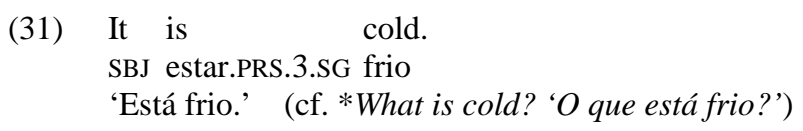

Como, nesse caso, o Sujeito não corresponde a nenhuma unidade semântica ou pragmática subjacente, trata-se de um fenômeno verdadeiramente morfossintático.

A noção de Sujeito pertence, como já demonstraram Van Valin e LaPolla (1997) e outros, tanto às línguas nominativo-acusativas quanto às línguas absolutivo-ergativas. Nas línguas nominativo-acusativas a neutralização se produz entre o único argumento (com a função semântica de Ator ou Paciente) de uma estrutura monoargumental e o argumento com a função semântica de Ator de uma estrutura biargumental, como se esquematiza na Tabela 1:

\begin{tabular}{|l|l|l|}
\hline & Monoargumental & Biargumental \\
\hline Ator & Nominativo & \multicolumn{2}{|l}{} \\
Paciente & & Acusativo \\
\hline
\end{tabular}

Tabela 1: Alinhamento nominativo-acusativo

Nas línguas absolutivo-ergativas, é o Paciente das estruturas biargumentais que apresenta uma forma idêntica à do único argumento (com a função semântica de Ator ou Paciente) das estruturas monoargumentais, como se esquematiza na Tabela 2: 


\begin{tabular}{|l|l|l|}
\hline & Monoargumental & Biargumental \\
\hline Ator & \multicolumn{2}{|c}{ Ergativo } \\
\cline { 1 - 1 } Paciente & Absolutivo & \\
\hline
\end{tabular}

Tabela 2: Alinhamento absolutivo-ergativo

Na Tabela 1, o caso acusativo só distingue o Paciente de predicações biargumentais; na Tabela 2, o caso ergativo só distingue o Ator de predicações biargumentais.

Além dos fenômenos de neutralização que acabamos de mostrar, há operações especiais que podem fazer com que se atribua o Sujeito a argumentos com várias funções semânticas. Um exemplo óbvio é a passivização em línguas nominativo-acusativas como o Inglês, que permite que um argumento não-Ator se torne Sujeito, como se vê em (33) e (34):

(32) The man gave the book to the boy.

DEF homem dar.PST DEF livro R DEF rapaz

'O homem deu o livro ao rapaz.'

(33) The book was given to the boy by the man.

DEF livro AUX dar.PRT $R$ DEF rapaz A DEF homem

'O livro foi dado ao rapaz pelo homem.'

(34) The boy was given the book by the man.

DEF rapaz AUX dar.PRT DEF livro A DEF homem

"lit. o rapaz foi dado o livro pelo homem"

'O livro foi dado ao rapaz pelo homem.'

Nas línguas absolutivo-ergativas, encontramos a antipassivização, que atribui a um argumento não-Paciente a função de Sujeito da oração. Considere os exemplos bascos em (35) e (36), extraídos de Hualde e Urbina (2003: 431):

(35) Gutun hau (U) zuk (A) idatzia da. carta PROX.ABS 2SG.ERG escrever.PRF.DET AUX.3.SG

'Esta carta foi escrita por ti.'

(Paciente $(\mathrm{U})=$ Sujeito)

(36) $\mathrm{Ni}(\mathrm{A})$ gutun asko (U) idatzia naiz. $\quad$ (Ator (A) $=$ Sujeito)

1.SG carta muito.ABS escrever.PRF.DET AUX.1.SG

'Eu escrevi muitas cartas.'

$($ Ator $(\mathrm{A})=$ Sujeito $)$ 
É a forma do verbo auxiliar que trai a presença da voz antipassiva.

Esse argumento também se aplica à função sintática de Objeto. Considerem-se os exemplos da língua Kham (Watters 2002: 67-68, 313) contidos em (37-39). Esses exemplos exibem neutralizações entre o Paciente (U) numa predicação biargumental (37), o Recipiente (R) numa predicação biargumental (38) e o Recipiente (R) numa predicação triargumental (39):

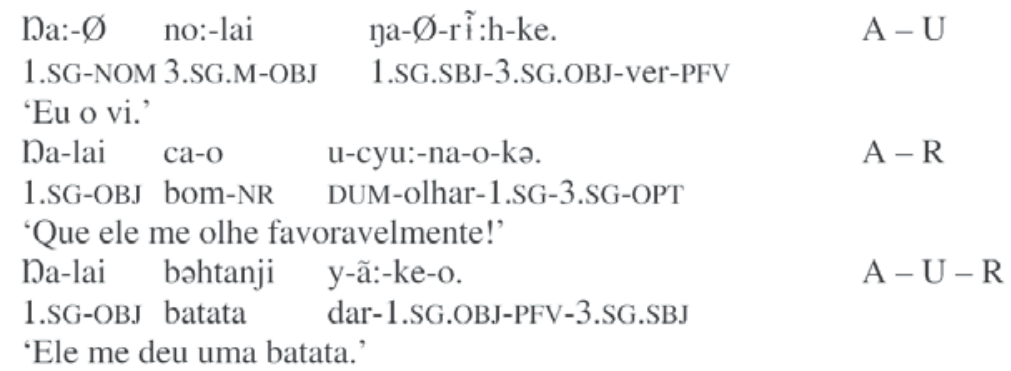

Todos os argumentos neutralizados apresentam o mesmo marcador de caso lai e induzem ao uso do mesmo tipo de concordância no verbo. Nessa língua não há outra maneira de exprimir esses argumentos. Haspelmath (2007) chama esse tipo de alinhamento de Primativo-Secundativo. Esta neutralização envolve a função sintática de Objeto e pode ser visualizada na Tabela 3:

\begin{tabular}{|l|c|l|}
\hline & Biargumental & Triargumental \\
\cline { 1 - 1 } Paciente & \multicolumn{2}{|c}{ Secundativo } \\
\cline { 1 - 1 } Recipiente & Primativo \\
\hline
\end{tabular}

Tabela 3: Alinhamento primativo-secundativo

Em Inglês, temos um alinhamento diferente, a saber, o alinhamento Diretivo-Indiretivo, como se vê nos exemplos (40-42):

$\begin{array}{lllll}\text { (40) He bought a } & \text { book. } & \\ & \text { 3.SG comprar.PST INDEF livro } & \\ \text { 'Ele comprou um livro.' } & & \\ \text { (41) He spoke to Sheila. } & \\ \text { 3.SG falar.PST R Sheila } & & \\ \text { (42) } & \text { He gle falou com a Sheila.' } & & \\ & \text { 3.SG dar.PST INDEF livro } \mathrm{R} & \text { Sheila } \\ & \text { 'Ele deu um livro à Sheila.' } & & \end{array}$


Se nos basearmos só nesses exemplos, não temos nenhuma justificativa para postular uma função de Objeto em Inglês, visto não haver neutralização: os Pacientes comportam-se como Pacientes, os Recipientes como Recipientes, como se visualiza na Tabela 4:

\begin{tabular}{|c|c|c|}
\hline & Biargumental & Triargumental \\
\hline Paciente & \multicolumn{2}{|c|}{ Diretivo } \\
\hline Recipiente & \multicolumn{2}{|c|}{ Indiretivo } \\
\hline
\end{tabular}

Tabela 4: Alinhamento diretivo-indirectivo

Mas existe também a possibilidade de atribuir a função de Objeto ao argumento com função semântica de Recipiente, de que resulta (43):

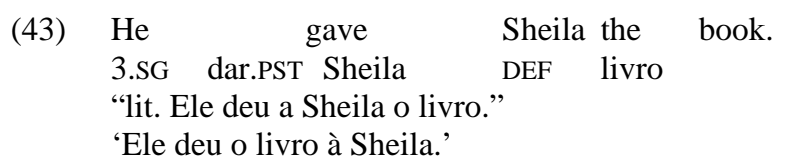

Aqui se vê uma neutralização das propriedades formais do Paciente (numa estrutura biargumental) e do Recipiente, igual à situação em Kham (37)-(39).

Muitas línguas dispõem de uma forma verbal especial, chamada de "aplicativa”, que marca a atribuição da função de Objeto a um argumento não-Paciente. Eis dois exemplos da Língua Padrão da Indonésia:

(44) Saya memanggang roti untuk Eric.

1.SG A.cozer pão para Eric

'Eu cozi pão para o Eric.'

(45) Saya memanggang-kan Eric roti.

1.SG A.bake-APPL Eric bread

'lit. Eu cozi o Eric pão.'

'Eu cozi pão para o Eric.'

Podemos agora estabelecer uma tipologia de línguas, começando com as que não atribuem relevância às funções sintáticas, como o Achém, que dispõem de um sistema de alinhamento puramente representacional, conforme se vê na Tabela 5: 


\begin{tabular}{|c|l|l|l|}
\hline & Monoargumental & Biargumental & triargumental \\
\hline A & Ator & & \\
\hline U & Paciente & \\
\hline R & Recipiente \\
\hline
\end{tabular}

Tabela 5: Alinhamento puramente semântico

Procedemos, a seguir, com um sistema com Sujeito. A Tabela 6 mostra um sistema nominativo-acusativo com alinhamento diretivo-indiretivo:

\begin{tabular}{|c|c|c|c|}
\hline & Monoargumental & Biargumental & Triargumental \\
\hline $\mathrm{A}$ & \multirow[t]{3}{*}{ Sujeito } & & \\
\hline $\mathrm{U}$ & & Paciente & \\
\hline $\mathrm{R}$ & & Recipiente & \\
\hline
\end{tabular}

Tabela 6: Sujeitos em sistemas nominativo-acusativos/diretivo-indiretivos

Já a Tabela 7 exibe um sistema absolutivo-ergativo igualmente com alinhamento diretivo-indiretivo.

\begin{tabular}{|l|l|l|l|}
\hline & Monoargumental & Biargumental & Triargumental \\
\hline $\mathrm{U}$ & Sujeito & \multicolumn{1}{l}{} \\
\cline { 1 - 1 } $\mathrm{A}$ & & Ator \\
\cline { 3 - 4 } $\mathrm{R}$ & & Recipiente \\
\hline
\end{tabular}

Tabela 7: Sujeitos em sistemas absolutivo-ergativos/diretivo-indiretivos

Como exemplos desses sistemas, temos, respectivamente, o Francês e o Basco. Se também permitirmos a operação da função de Objeto, teremos a configuração apresentada na Tabela 8 , que mostra uma língua nominativo-acusativa com alinhamento primativo-secundativo, tal como o Kham:

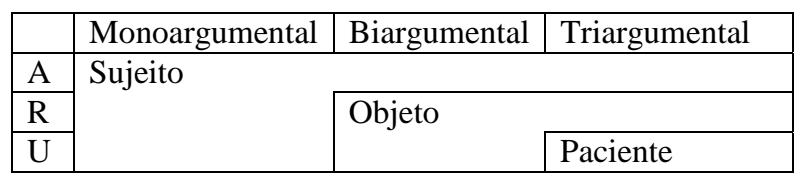

Tabela 8: Sujeitos e Objetos em sistemas nominativo-acusativos/ primativo-secundativos 
Quanto às línguas absolutivo-ergativas, porém, deparamos com uma situação diferente. Considere que, numa língua, o Paciente de uma predicação biargumental se comporte como o único argumento de uma predicação monoargumental (isso é o alinhamento absolutivo-ergativo); considere também que o Recipiente numa predicação triargumental se comporte como o Paciente numa predicação biargumental (isso é o alinhamento primativo-secundativo); em ambos os casos, então a função de Sujeito do único argumento de uma predicação monoargumental e do Paciente de uma predicação biargumental se estenderá cumulativamente ao Recipiente da predicação triargumental. Esse argumento, o Recipiente, usurpa assim a função de Sujeito, desfavorecendo a de Paciente. O resultado é apresentado na Tabela 9. Nesse sistema, é irrelevante a função de Objeto:

\begin{tabular}{|l|l|l|l|}
\hline & monoargumental & Biargumental & Triargumental \\
\cline { 1 - 1 } $\mathrm{R}$ & Sujeito & \multicolumn{2}{|c}{} \\
\cline { 1 - 1 } $\mathrm{U}$ & & & Paciente \\
\cline { 1 - 1 } $\mathrm{A}$ & & Ator & \\
\hline
\end{tabular}

Tabela 9: Sujeitos em sistemas absolutivo-ergativos/primativo-secundativos

Como argumenta Dryer (1986: 818), em tais línguas é a mesma marcação que caracteriza o único argumento da predicação monoargumental, o Paciente da predicação biargumental e o Recipiente da predicação triargumental. Esse autor ilustra essa situação com os exemplos da língua Tzotzil, contidos em (46-48):

(46) Vinik-on.

$\mathrm{U}$

homem-ABS.1.SG

'Eu sou um homem.'

(47) Mi č-a-mah-on.

$\mathrm{A}-\mathrm{U}$

Q ASP-ERG.2.SG-bater-ABS.1.SG

'Você vai bater em mim?'

(48) Mi mu š-a-čon-b-on

1-a-čitome. $\quad \mathrm{A}-\mathrm{U}-\mathrm{R}$

Q NEG ASP-ERG.2.SG-vender-BEN-ABS.1.SG DEF-2.SG.POSS-porco

'Não quer me vender os seus porcos?'

O marcador da primeira pessoa no caso absolutivo -on encontra-se no único argumento de (46), no Paciente de (47) e no Recipiente de (48). 
O fato de uma língua se servir de funções sintáticas não significa que sua organização gramatical dependa completamente dessas funções. Em Chickasaw (Munro e Gordon 1982, citados por Bickel no prelo), a concordância verbal obedece ao alinhamento representacional, como se vê em (49-51):
(49) a. Malili-li. correr-1.SG.A 'Eu corri.'
b. Chi-sso-li. 2.SG.U-bater-1.SG.A 'Eu bati em você.'
(50) a. Sa-chokma. 1.SG.U-bom 'Eu sou bom.'
(51) a. An-takho'bi 1.SG.R-preguiçoso 'Eu sou preguiçoso.'
b. Is-sa-thaana. 2.SG.A-1.SG.U-conhecer
'Você me conhece.'
b. Iss-am-a 2.SG.A-1.SG.R-dar 'Você me deu aquilo.'

Observa-se que não se altera a marcação do Ator, do Paciente e do Recipiente, seja qual que for a valência da estrutura em que ocorrem. São as funções semânticas dos argumentos que determinam a expressão, mas no sistema de mudança de referência em Chickasaw, existe alinhamento nominativo-acusativo, isto é, um alinhamento morfossintático: o único argumento de uma predicação intransitiva alinha-se com o Ator de uma predicação biargumental, como se vê nos exemplos (52) e (53):
(52) Top-at tiwwa-li-kat sa-hotolhko-tok.
Cama-NOM estar_deitado-1.SG.A-SUB.SS 1.SG.U-tossir-PST 'Deitado na cama, eu tossi.'
(53) Alhponi' aa-sa-bashafa-kã Bonnie-akot sa-bashaffi-tok. cozinha L-1.SG.U-ser.cortado-SUB.DS Bonnie-CONTR.NOM 1.SG.U-cortar-PST 'Eu fui cortado na cozinha, e foi a Bonnie que o fez.'

A primeira oração em (52) apresenta a marcação "mesmo sujeito" (SS) e a primeira pessoa é Ator-de-uma-predicação-transitiva na primeira oração, mas Paciente na segunda. Em (53), a primeira oração apresenta a marcação "sujeito diferente" (DS) e a primeira pessoa é Paciente-de-umapredicação-intransitiva na primeira oração, mas Paciente-de-uma-predicação-transitiva na segunda. Esses dois fenômenos sinalizam a presença da atribuição da função de Sujeito (regendo as marcações "mesmo sujeito" e "sujeito diferente"). 
Em tais bases, podemos agora elaborar algumas generalizações sobre a acessibilidade de diferentes tipos de argumentos às funções de Sujeito e de Objeto. Adotamos a distinção feita por Van Valin e LaPolla (1997) entre as hierarquias de acessibilidade nas línguas nominativo-acusativas e nas absolutivo-ergativas, às quais adicionamos a função de Recipiente. O resultado acha-se exposto na Tabela 10:

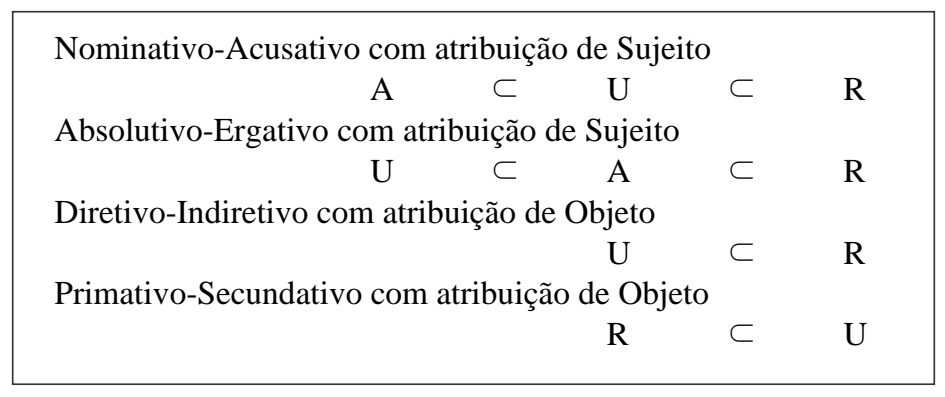

Tabela 10: Generalizações sobre accessibilidade a Sujeito e Objeto

Coloca-se, agora, uma questão relevante: como as línguas "escolhem" que argumentos vão se tornar Sujeito ou Objeto, caso existam as possibilidades fornecidas pela passivização, pela antipassivização, pela dativização ou pela construção aplicativa? Se essas escolhas fossem determinadas inteiramente nos Níveis Interpessoal e Representacional, não teríamos de postular funções sintáticas. Acreditamos que a resposta mais plausível seja a de que os fatores que conduzem à atribuição da função de Sujeito e/ou de Objeto se aplicam fora da gramática, no componente contextual do modelo global da comunicação verbal. Bolkestein (1985) e Bolkestein e Risselada (1987) admitem que o fator crucial para determinar essas escolhas é o da coesão textual. Essas autoras descobriram a existência de uma relação entre a atribuição da função Sujeito em Latim e o fato de as entidades referenciadas já terem sido mencionadas no discurso precedente ou poderem ser deduzidas do conteúdo do discurso. Essa informação se armazena no componente contextual do modelo global e pode ser invocada no processo de codificação morfossintática.

\subsubsection{Complexidade}

Pode-se determinar o alinhamento morfossintático não somente com base nas funções sintáticas, mas também com base na complexidade rela- 
tiva dos constituintes. Em muitas línguas, colocam-se as orações subordinadas facultativamente na posição final da oração superordenada, independentemente do fato de a oração ser uma completiva, relativa ou adverbial. Veja os exemplos ingleses contidos em (54-56):

(54) a That he has left is a pity.

b It is a pity that he has left.

'É uma pena que ele já tenha ido embora.'

(55) a That man that you met in the train yesterday has left.

b The man has left that you met in the train yesterday.

'O homem que você conheceu no trem ontem já saiu.'

(56) a The man left because he can't stand smoke.

b Because he can't stand smoke the man left.

'O homem foi-se embora porque não suporta fumo.'

Em (54a), a completiva encontra-se na posição do Sujeito; orações com essa função preferem, por assim dizer, a posição final da sentença, inserindo-se um pronome vazio na posição do Sujeito, como se vê em (54b). Em (55a), a oração relativa ocupa a posição de um modificador no sintagma nominal, mas pode ser submetida à extraposição para a posição final, como ocorre com (55b). A oração adverbial em (56a) pode aparecer quer em posição inicial quer em posição final, mas sem interferência de outros fatores, ocorre preferencialmente na posição final. Visto que os papéis semânticos das orações são diferentes, deve ser a constituição morfossintática que determina o comportamento paralelo. Esta mesma tendência manifesta-se ainda mais claramente na camada dos sintagmas. Considere os exemplos ingleses contidos em (57) e (58):

(57) a the singing detective

b *the detective singing

' $\mathrm{O}$ detetive cantor'

(58) a the detective who is singing

b *the who is singing detective

'O detetive que está cantando'

Já vimos que as línguas podem dispor de uma posição especial para constituintes pesados. De forma analógica, podem dispor de uma posição especial para constituintes leves, tais como clíticos, independentemente das categorias semânticas que eles expressam. Em Francês, por exemplo, há uma posição pré-verbal que hospeda tanto clíticos pronominais como o clítico negativo ne, como se vê nos exemplos de (59-62): 

(59) a Marie voit Jean. Maria ver.PRS.3.SG João

\section{Conclusão}

Em resumo, dado que a arquitetura da GDF é dotada de níveis separados de organização interpessoal, representacional e morfossintática, essa organização modular esclarece o problema de alinhamento. Vimos que é preciso distinguir três tipos: no alinhamento interpessoal, a organização morfossintática reflete aspectos do Nível Interpessoal; no alinhamento representacional, a organização morfossintática reflete aspectos do Nível Representacional; e, finalmente, no alinhamento morfossintático, o Nível Morfossintático impõe a sua própria organização às entradas que provêm dos outros níveis. Essas correlações permitem prever que as línguas diferem na medida em que favorecem um ou outro tipo de alinhamento. Desfavorece o alinhamento morfossintático uma língua em que as funções sintáticas estão ausentes e a complexidade dos constituintes não desempenha um papel relevante. É possível predizer também que tais línguas atribuirão um grau maior de importância ao alinhamento interpessoal e/ou representacional. E assim por diante.

O trabalho recente de Bakker e Siewierska (2007), que defende uma posição essencialmente semelhante à nossa, torna o assunto ainda mais 
complexo ao apontar a influência de alguns fatores imprevistos. Em Georgiano, é o tempo do estado-de-coisas que afeta o alinhamento e, em Yidin ${ }^{y}$, é a qualidade nominal ou pronominal dos argumentos que codetermina o alinhamento. Além disso, ao investigar várias línguas da Austronésia, Foley (2005) mostra que elas diferem sistematicamente num eixo semântico que determina quais argumentos funcionam como Atores e quais como Pacientes. O quadro que se pintou neste artigo é, portanto, simples demais, mas deixa suficientemente claro que a GDF fornece um suporte teórico adequado para a investigação futura dos fenômenos relacionados com o alinhamento.

\section{Abreviaturas}

\section{No texto}

$\begin{array}{ll}\text { A } & \text { Ator } \\ \text { DIR } & \text { Marcação Direta } \\ \text { GDF } & \text { Gramática Discursivo-Funcional } \\ \text { INV } & \text { Marcação Invertida } \\ \text { L } & \text { Lugar } \\ \text { R } & \text { Recipiente } \\ \text { U } & \text { Paciente }\end{array}$

Nas glosas e nas representações formais

$\begin{array}{ll}+\mathrm{i} & \text { identificável } \\ +\mathrm{s} & \text { específico } \\ 1 & \text { primeira pessoa } \\ 2 & \text { segunda pessoa } \\ 3 & \text { terceira pessoa } \\ \mathrm{A} & \text { ator } \\ \text { ABS } & \text { absolutivo } \\ \text { APPL } & \text { aplicativo } \\ \text { ASP } & \text { aspecto } \\ \text { AUX } & \text { auxiliar } \\ \text { BEN } & \text { beneficiário } \\ \text { CONTR } & \text { contraste } \\ \text { DAT } & \text { dativo } \\ \text { DEF } & \text { definido } \\ \text { DET } & \text { determinador } \\ \text { DIR } & \text { direto }\end{array}$




$\begin{array}{ll}\text { DSsujeito diferente } \\ \text { DUM } & \text { vazio (dummy) } \\ \mathrm{e}_{1} & \text { estado-de-coisas } \\ \text { ERG } & \text { ergativo } \\ \mathrm{f}_{1} & \text { propriedade } \\ \text { FAM } & \text { informal } \\ \text { GER } & \text { gerúndio } \\ \text { IMPF } & \text { imperfetivo } \\ \text { INCH } & \text { incoativo } \\ \text { INDEF } & \text { indefinido } \\ \text { INSTR } & \text { instrumento } \\ \text { INV } & \text { invertido } \\ \text { L } & \text { locativo } \\ \text { LNK } & \text { ligação } \\ \text { NEG } & \text { negativo } \\ \text { NOM } & \text { nominativo } \\ \text { NONTOP } & \text { não-tópico } \\ \text { NR } & \text { nominalizador } \\ \text { OBJ } & \text { objeto } \\ \text { OBL } & \text { oblíquo } \\ \text { OBV } & \text { obviativo } \\ \text { OPT } & \text { optativo } \\ \text { PFV } & \text { perfetivo } \\ \text { PL } & \text { plural } \\ \text { POL } & \text { cortês } \\ \text { POSS } & \text { possessivo } \\ \text { PROX } & \text { próximo } \\ \text { PRS } & \text { tempo presente } \\ \text { PST } & \text { tempo passado } \\ \text { Q } & \text { interrogativo } \\ \text { R } & \text { recipiente } \\ \text { SBJ } & \text { sujeito } \\ \text { SG } & \text { singular } \\ \text { SPEC } & \text { específico } \\ \text { SS } & \text { mesmo sujeito } \\ \text { SUB } & \text { subordinador } \\ \text { TNS } & \text { tempo } \\ \text { TOP } & \text { tópico } \\ \text { U } & \text { paciente } \\ & \text { indivíduo } \\ \end{array}$

Recebido em outubro de 2007.

Aprovado em outubro de 2008.

E-mail: lachlan_mackenzie@hotmail.com

p.c.hengeveld@uva.nl 


\section{REFERÊNCIAS BibLIOGRÁFICAS}

Aissen, Judith. 1983. Indirect Object advancement in Tzotzil. In: David Perlmutter. (Eds.) Studies in Relational Grammar I. Chicago: University of Chicago Press.

Bakker, Dik \& Anna Siewierska. 2007. Another take on the notion Subject. In: Mike Hannay \& Gerard Steen. (Eds.) Structural-Functional Studies in English Grammar. Amsterdã/Filadélfia: John Benjamins.

Bickel, Balthasar. No prelo. Grammatical relations typology. In: Jae-Jung Song. (Eds.) The Oxford Handbook of Typology. Oxford: Oxford University Press.

BolKesteIn, A. Machtelt. 1985. Discourse and case-marking: Three-place predicates in Latin. In: Christian Touratier. (Ed.) Syntaxe et latin. Aixen-Provence: Université de Provence.

\& Rodie Risselada. 1987. The pragmatic motivation of syntactic and semantic perspective. In: Jef Verschueren \& Marcella BertuccelliPapi. (Eds.) The Pragmatic Perspective. Amsterdã/Filadélfia: John Benjamins.

Cole, Peter \& Min-Jeong Son. 2004. The Argument structure of verbs with the suffix -kan in Indonesian. Oceanic Linguistics. 43.2: 339-364.

Dryer, Matthew S. 1986. Primary Objects, Secondary Objects, and Antidative. Language. 62: 808-845.

DurIE, Mark. 1985. A Grammar of Acehnese: On the Basis of a Dialect of North Aceb (Verhandelingen van het Koninklijk Instituut voor Taal-, Landen Volkenkunde 112). Dordrecht/Cinnaminson: Foris.

Falk, Yehuda N. 2006. Subjects and Universal Grammar: An Explanatory Theory (Cambridge Studies in Linguistics 113). Cambridge: Cambridge University Press.

Foley, William A. 2005. Semantic parameters and the unaccusative split in the Austronesian language family. Studies in Language 29.2: 385430.

Haspelmath, Martin 2007. Ditransitive alignment splits and inverse alignment. Functions of Language 14.1: 79-102.

Hengeveld, Kees \& J. Lachlan Mackenzie. 2008. Functional Discourse Grammar. Oxford: Oxford University Press.

Himmelmann, Nikolaus P. 2005. Tagalog'. In: Karl Alexander Adelaar \& Nikolaus P. Himmelmann. (Eds.). The Austronesian Languages of Asia and Madagascar. Londres: Routledge. 
Hualde, José Ignacio \& Jon Ortiz de Urbina. 2003. A Grammar of Basque (Mouton Grammar Library 26). Berlim/Nova Iorque: Mouton de Gruyter.

KeEnan, Edward. 1976. Towards a universal definition of "subject". In: Charles N. Li. (Ed.) Subject and Topic. Nova Iorque: Academic Press.

Miller, Philip H. and Ivan A. Sag. 1997. French clitic movement without clitics or movement. Natural Language and Linguistic Theory 15: 573-639.

Munro, Pamela \& Lynn Gordon, Lynn. Syntactic relations in Western Muskogean. Language 58: 81-115.

Siewierska, Anna \& Dik Bakker. No prelo. Three takes on grammatical relations: a view from the languages of Europe and North and Central Asia. In: Bernard Comrie \& Valery Solovyev. (Eds.) Argument Structure in the Languages of Northern Eurasia. Amsterdã/Filadélfia: John Benjamins.

Van Valin, Jr, Robert D. \& Randy LaPolla. 1997. Syntax: Structure, Meaning and Function. Cambridge: Cambridge University Press.

W AtTers, David E. 2002. A Grammar of Kham (Cambridge Grammatical Descriptions). Cambridge: Cambridge University Press.

Wolvengrey, Arok. 2005. Inversion and the absence of grammatical relations in Plains Cree. In: Casper de Groot \& Kees Hengeveld. (Eds.) Morphosyntactic Expression in Functional Grammar (Functional Grammar Series 27). Berlim/Nova Iorque: Mouton de Gruyter. 